\title{
Dietary patterns and associated factors among the elderly
}

\author{
Marcela Previato do Nascimento Ferreira' \\ Ágatha Nogueira Previdelli ${ }^{1}$ \\ Tatiana Império de Freitas \\ Karina Maffei Marques \\ Rita Maria Monteiro Goulart ${ }^{\top}$ \\ Rita de Cássia de Aquino?
}

\section{Abstract}

The aim of the present study was to identify dietary patterns among the elderly, and associate the same with sociodemographic characteristics, health and lifestyle. A crosssectional study was carried out with a non-probabilistic sample of 295 elderly residents of both genders of the city of São Caetano do Sul, São Paulo, Brazil, who were users of public health units. Dietary patterns were identified considering 44 food items identified through 24-hour dietary recall. Factor analysis by the principal components method was used, adopting loads greater than 0.25 as the cut-off point, followed by Varimax orthogonal rotation. The associations were analyzed by the linear regression method, with variables with $p<0.20$ in univariate regression selected, and those with $p<0.05$ maintained in the multivariate model. There was a greater percentage of elderly females (85.1\%) and those aged 60-69 years (46.4\%). Three dietary patterns were identified: the "traditional" pattern was associated with the male gender $(\beta=0.59, p<0.001)$ and physically active individuals $(\beta=0.39, p=0.020)$; the "Pastas, pork and sweets" pattern was associated with the male gender $(\beta=0.38, p=0.025)$ and retired individuals $(\beta=0.55$, $p=0.017)$; and the "Coffee with milk and bread and butter" pattern was associated with an age of 80 years or older $(\beta=0.55, p=0.004)$ and elderly persons who had difficulty chewing $(\beta=0.38, p=0.013)$. The dietary patterns identified show that the elderly tend to maintain similar eating habits to the Brazilian population in general, and that diet changes to a similar degree as health and life style conditions.

\footnotetext{
Universidade São Judas Tadeu, Programa de Pós Graduação Strictu Sensu em Ciências do Envelhecimento. São Paulo, SP, Brasil.
}

Keywords: Aging. Food consumption. Factor Analysis, Statistical. 


\section{INTRODUCTION}

Knowledge of the food consumption of an individual of any age group is essential to the evaluation of their nutritional status. Studies are therefore carried out to identify eating habits and their possible correlation with health status. The Academy of Nutrition and Dietetics ${ }^{1}$ analyzed factors that may interfere in the choice of foods, such as age, socioeconomic conditions, psychosocial factors, environmental conditions, lifestyle, religion and body composition, which are affected by influences such as governmental sectors, private industry and marketing.

One of the ways to analyze food consumption is to identify dietary patterns, which consists of evaluating the main food groups consumed by individuals or groups, and correlating these with their characteristics, such as aging.

Studies that seek to identify dietary patterns in the elderly are scarce both in Brazilian ${ }^{2,3}$ and international literature $^{4-7}$, despite the importance of this issue for the scientific community. Food consumption is directly related to nutritional status and consequently to the emergence or non-emergence of diseases, in particular Chronic Noncommunicable Diseases, which tend to increase with advancing age.

In non-Brazilian literature, Anderson et al. ${ }^{8}$ identified six dietary patterns among 3,075 elderly people from different regions of the United States who participated in the Health, Aging and Body Composition - Health ABC study, related to the influence of genotyping and insulin sensitivity.

In Brazil, Ferreira et al. ${ }^{2}$ carried out a study with 355 elderly people in the city of Botucatu, São Paulo, and identified the following patterns: Healthy, Snacks and weekend meal, Fruits, Light and Integral, Soft diet and Traditional, and verified their adherence to sociodemographic characteristics.

Given the specificities of the aging process, the demographic transition that Brazil is undergoing and the importance of nutrition in factors that affect the quality of life of the elderly, it is necessary to carry out studies to identify the food choices of such individuals in order to support public policies and nutritional counseling among this age group.
The objective of the present study was to identify the dietary patterns of elderly users of public health units living in the municipal region of São Caetano do Sul, São Paulo, Brazil, and to associate these with sociodemographic variables, nutritional status and lifestyle.

\section{METHODS}

A descriptive cross-sectional study was performed with 295 elderly individuals, aged 60 years and older, of both genders, who were users of public health units in the municipal region of São Caetano do Sul, São Paulo, Brazil, distributed among the districts of the city. Data collection took place over twelve months between February 2014 and February 2015.

The sample studied was non-probabilistic and chosen for convenience, and the sample size was determined according to the main objective of evaluating the diet of the elderly. The methodology of Hair et al. ${ }^{9}$ was applied, which states that the sample size should be five times greater than the number of items in the Food Frequency Questionnaire (FFA), which contains 57 groups. In addition, a sample of at least 288 individuals was estimated for multivariate regression analysis, guaranteeing a $95 \%$ confidence level, and a sampling error of $5 \%$ was applied. All the elderly persons registered with the public health units that agreed to participate were included, while those with cognitive deficits who were unable to respond to the interview were excluded.

Data were collected by a team of trained nutritionists who displayed posters at public health units and conducted daily visits during local activities, inviting the elderly to participate and explaining the objectives and procedures. Those who were interested in participating provided their name and telephone number, and were informed of the date and time of the appointment of their choice, with a nutritionist contacting them 24 hours earlier to confirm. A structured questionnaire was developed based on the Saúde, Bem-estar e Envelhecimento (the Health, Welfare and Aging) survey of the Pan American Health Organization (SABE/OPAS ${ }^{10}$. Socio-demographic data (age, gender, schooling, marital status, family composition and income) were collected, as well as clinical and lifestyle data (smoking, reported morbidities/diseases, use of 
nutritional supplements, oral cavity conditions and gastrointestinal tract). The elderly declared whether they performed physical activity or did not perform physical activity, regardless of the frequency and/or intensity of the same. The per capita income was calculated by the amount received per month (retirement, family allowance, rent or bank investments, government programs and others) divided by the minimum salary applicable in 2014, which was $\mathrm{R} \$ 724.00$.

Anthropometric variables were used to verify nutritional status, with weight and height measured to calculate the body mass index (BMI=weight in $\mathrm{kg} /$ height in $\mathrm{m}^{2}$ ) and waist circumference (WC) also measured. BMI was classified according to age group, as recommended by the Pan American Health Organization ${ }^{11}$, into underweight $(\mathrm{BMI}<23$ $\left.\mathrm{kg} / \mathrm{m}^{2}\right)$, normal weight $\left(\mathrm{BMI} \geq 23\right.$ and $\left.<28 \mathrm{~kg} / \mathrm{m}^{2}\right)$, overweight (BMI $\geq 28$ and $<30 \mathrm{~kg} / \mathrm{m}^{2}$ ) and obesity $\left(\mathrm{BMI} \geq 30 \mathrm{~kg} / \mathrm{m}^{2}\right)$. The World Health Organization (WHO) standard, which predicts the risk of metabolic complications associated with obesity, was used in the classification of waist circumference, based on gender, as follows: high risk for men (WC $\geq 94 \mathrm{~cm}$ ) and women $(\mathrm{WC} \geq 80 \mathrm{~cm})$ and very high risk for men (WC $\geq 102$ ) and women (WC $\geq 88 \mathrm{~cm}$ ).

A 24-hour dietary recall (24HR) was used to identify food consumption. The elderly were instructed to note the food consumed on the eve of the interview in order to reduce the risk of forgetfulness. The 24HRs were analyzed to transform the quantities of the foods and preparations described into the usual measures of grams or milliliters. The data obtained from the 24HRs were entered in the Nutrition Data System for Research (NDS-R) software program $^{12}$.

The interviews were conducted in order to contemplate all the days of the week and months of the year, considering the variability of the patterns of food consumption in different seasons.

To obtain the dietary patterns, exploratory factorial analysis by principal components (PCA) was performed, considering the food from the $\mathrm{R} 24 \mathrm{H}$ in grams or milliliters. The 529 foods/beverages reported in 24HR were grouped based on the 57 items of the Food Frequency Questionnaire (FFQ) adapted for the present study ${ }^{13}$, with those that were not reported by at least $5 \%$ of the elderly persons excluded. Following a number of regrouping tests based on nutritional similarity, 44 food items were maintained to identify dietary patterns.

In the first phase of PCA, the Cattell plot (scree plot) was evaluated and 19 consumption patterns with eigenvalues greater than 1.0 were identified. This value indicates a greater ability to explain the variance of the data than an original variable could describe individually ${ }^{14,15}$.

Varimax orthogonal rotation was then used to increase the interpretability of the data and the food items the factor loading of which was greater than 0.25 were maintained in the matrix. To verify the appropriateness of the use of the analysis, the uniformity of the data was tested by the KaiserMeyer-Olkin test, and presented a satisfactory result (0.56). The homogeneity of variance was confirmed by the Bartlett sphericity test $(p<0.001)$. The scores of each participant were computed to identify the factors associated with the patterns obtained ${ }^{14}$.

The study variables were categorized with the purpose of performing descriptive and inferential statistical analysis, and a significance level of $5 \%$ was adopted.

For inferential analysis of the identified dietary patterns, the linear regression method was chosen, with the scores obtained in each pattern for each individual used as the dependent variable. In univariate linear regression analysis, independent variables that obtained a value of $p<0.20$ were selected for inclusion in multiple regression and the model was adjusted by gender. The stepwise forward strategy was used, and variables with $p<0.05$ were maintained in the final model. Measures of central tendency and dispersion were also calculated.

The study was approved by the Ethics Research Committee of the Fundação Municipal de Saúde de São Caetano do Sul (the Municipal Health Foundation of São Caetano do Sul) and the Universidade São Judas Tadeu (São Judas Tadeu University), according to approval $\mathrm{n}^{\circ} 71 / 2013$ and $\mathrm{n}^{\circ} 470.062$ (CAAE 24855113.6.0000.0089), respectively. A letter of consent was received from São Caetano do Sul City Council permitting the carrying out of the data collection and the participants signed a Free and Informed Consent Form (FICF). 


\section{RESULTS}

A total of 295 elderly people participated in the present study, of whom $85.1 \%$ were female, $46.4 \%$ were aged between 60 and 69 years old, $44.7 \%$ were married, $74.6 \%$ lived with a partner, $41.7 \%$ had from zero to four years of schooling, $62.4 \%$ were retired and $44.1 \%$ had a per capita income between one and three minimum salaries. Regarding health and lifestyle characteristics, 95.6\% were non-smokers, $84.7 \%$ practiced physical activity, $74.6 \%$ stated that their eating habits had not changed and $64.4 \%$ had not used food supplements in the last year. Regarding nutritional status, $43.7 \%$ of the elderly were overweight (overweight or obese) and more than half $(64.4 \%)$ presented a very high risk of metabolic complications associated with obesity.
Three dietary patterns were identified by factorial analysis, and were named according to the main food items that constituted each one, according to the foods habit of the Brazilian population and based on the contribution (factorial loading) of food items in each pattern. Pattern 1, entitled Traditional, explained $5.45 \%$ of consumption variation and presented food commonly consumed by the Brazilian population in main meals: beans, rice, vegetables, olive oil, vegetables and chicken. Pattern 2 (Pasta, pork and sweets), was so-called due to the presence of sweets, soft drinks, pasta with sauce and pork, explaining $4.94 \%$ of the variation of consumption. Finally, standard 3 (Coffee with milk and bread and butter) included foods that constitute a typical Brazilian breakfast or snack: butter/margarine, toast, bread, sugar, coffee and whole milk, which explained $4.69 \%$ of the variation in consumption. Together, the three patterns explained $15.08 \%$ of the total intake variance (Table 1).

Table 1. Factorial loads obtained by analysis of the major components of dietary patterns of the elderly. São Caetano do Sul, São Paulo, 2015.

\begin{tabular}{|c|c|c|c|}
\hline \multirow[b]{2}{*}{ Foods/Groups } & \multicolumn{3}{|c|}{ Dietary Patterns } \\
\hline & Traditional & Pasta, pork and sweets & $\begin{array}{l}\text { Cafe with milk and } \\
\text { bread with butter }\end{array}$ \\
\hline Beans & 0.6990 & 0.1461 & 0.1180 \\
\hline Rice & 0.6935 & -0.1942 & 0.0805 \\
\hline Vegetables & 0.5227 & -0.0870 & -0.2291 \\
\hline Olive oil & 0.5108 & -0.0938 & -0.2690 \\
\hline Vegetables \& cruciferous vegetables & 0.2783 & 0.1141 & 0.1380 \\
\hline Chicken & 0.2510 & 0.0535 & 0.0583 \\
\hline Pasta without sauce & -0.4022 & 0.0351 & -0.0773 \\
\hline Cream cheese & -0.3511 & -0.0591 & -0.0059 \\
\hline Sweets and ice cream & 0.0446 & 0.7699 & 0.0639 \\
\hline Soft drinks & 0.0252 & 0.6394 & -0.0244 \\
\hline Pasta with sauce & 0.0735 & 0.6281 & 0.0166 \\
\hline Pork & 0.0726 & 0.5671 & -0.2193 \\
\hline Butter/margarine & 0.1935 & -0.1056 & 0.4843 \\
\hline Toast & 0.0437 & -0.1338 & 0.4590 \\
\hline Bread & -0.0007 & -0.0772 & 0.4211 \\
\hline Sugar & -0.0087 & -0.1061 & 0.3545 \\
\hline Coffee & 0.1576 & 0.0049 & 0.3005 \\
\hline Whole milk & 0.0866 & -0.1075 & 0.2545 \\
\hline Yoghurt & 0.1405 & -0.1112 & -0.4558 \\
\hline Oilseeds & 0.0896 & -0.1911 & -0.3269 \\
\hline
\end{tabular}


continued from Table 1

\begin{tabular}{|c|c|c|c|}
\hline \multirow[b]{2}{*}{ Foods/Groups } & \multicolumn{3}{|c|}{ Dietary Patterns } \\
\hline & Traditional & Pasta, pork and sweets & $\begin{array}{l}\text { Cafe with milk and } \\
\text { bread with butter }\end{array}$ \\
\hline Cereals & 0.1049 & -0.0954 & -0.3244 \\
\hline Fish & 0.0260 & -0.1707 & -0.3040 \\
\hline Legumes & -0.0084 & -0.1421 & -0.2830 \\
\hline Skimmed milk & -0.1906 & 0.0498 & -0.1584 \\
\hline Cheeses & 0.0135 & 0.0406 & -0.0787 \\
\hline Sweet biscuits & -0.1281 & 0.1959 & -0.0534 \\
\hline Simple cake & -0.1684 & -0.1471 & 0.0565 \\
\hline Jelly/milk pudding & 0.0817 & -0.1055 & 0.2246 \\
\hline Root vegetables & -0.0875 & 0.0649 & -0.0148 \\
\hline Flours & -0.1055 & -0.0199 & -0.0945 \\
\hline Soups & -0.2331 & -0.0617 & 0.1385 \\
\hline Beef & 0.1603 & 0.1456 & 0.1781 \\
\hline Cold cuts & -0.0456 & -0.0056 & 0.0594 \\
\hline Fruit & -0.0547 & 0.1728 & -0.2050 \\
\hline Natural and concentrated juice & -0.1001 & -0.1016 & -0.2397 \\
\hline Processed juice & -0.0674 & -0.0465 & -0.0571 \\
\hline Teas & 0.0052 & -0.1701 & 0.0494 \\
\hline Chocolate & 0.0408 & 0.0889 & 0.0522 \\
\hline Chocolate milk & -0.0026 & 0.0646 & 0.0347 \\
\hline Tomato Sauce & -0.1498 & 0.0445 & 0.1137 \\
\hline Sweet bread & 0.0830 & -0.0103 & 0.1307 \\
\hline Salty crackers & -0.0540 & 0.0430 & -0.0116 \\
\hline Savory snacks, sandwiches and pizza & -0.2284 & -0.0275 & -0.1010 \\
\hline Tomatoes & 0.2320 & 0.0086 & -0.2023 \\
\hline Explained variance $(\%)$ & 5.45 & 4.94 & 4.69 \\
\hline Total explained variance (\%) & 5.45 & 10.39 & 15.08 \\
\hline
\end{tabular}

It should be noted that food items that contributed inversely to the pattern presented negative loads, indicating that they did not form part of the same consumption occasion. The Traditional pattern presented an inverse participation for the consumption of pasta without sauce $(-0.4022)$ and cream cheese (-0.3511) and the Coffee with mille and bread and butter pattern showed an inverse participation for yoghurts $(-0,4558)$, oilseeds $(-0.3269)$, cereals $(-0.3244)$, fish $(-0.3040)$, vegetables $(-0.2830)$ and olive oil $(-0.2690)$ (Table 1).

The degree to which each food item comprises the composition of the three consumption patterns can be seen in Figure 1.
In terms of the relationship between the characteristics of the elderly persons and dietary patterns, it was observed that the Traditional pattern was positively associated with males $(\beta=0.59, p<0.001)$ and those who performed physical activity $(\beta=0.39$, $p=0.020$ ), and inversely with elderly patients who used dental prostheses $(\beta=-0.25, p=0.034)$. In the Pasta, pork and sweets pattern, there were associations with males $(\beta=0.38, p=0.025)$ and retired elderly persons $(\beta=0.55$, $p=0.017)$. However, separated/divorced/widowed elderly persons $(\beta=-0.24, p=0.041)$ had an inverse association with this pattern. The Coffee with milk and bread and butter pattern was associated with age $\geq 80$ years $(\beta=0.55 ; p=0.004)$ and with elderly persons that had difficulty chewing $(\beta=0.38 ; p=0.013)$ (Table 2$)$. 


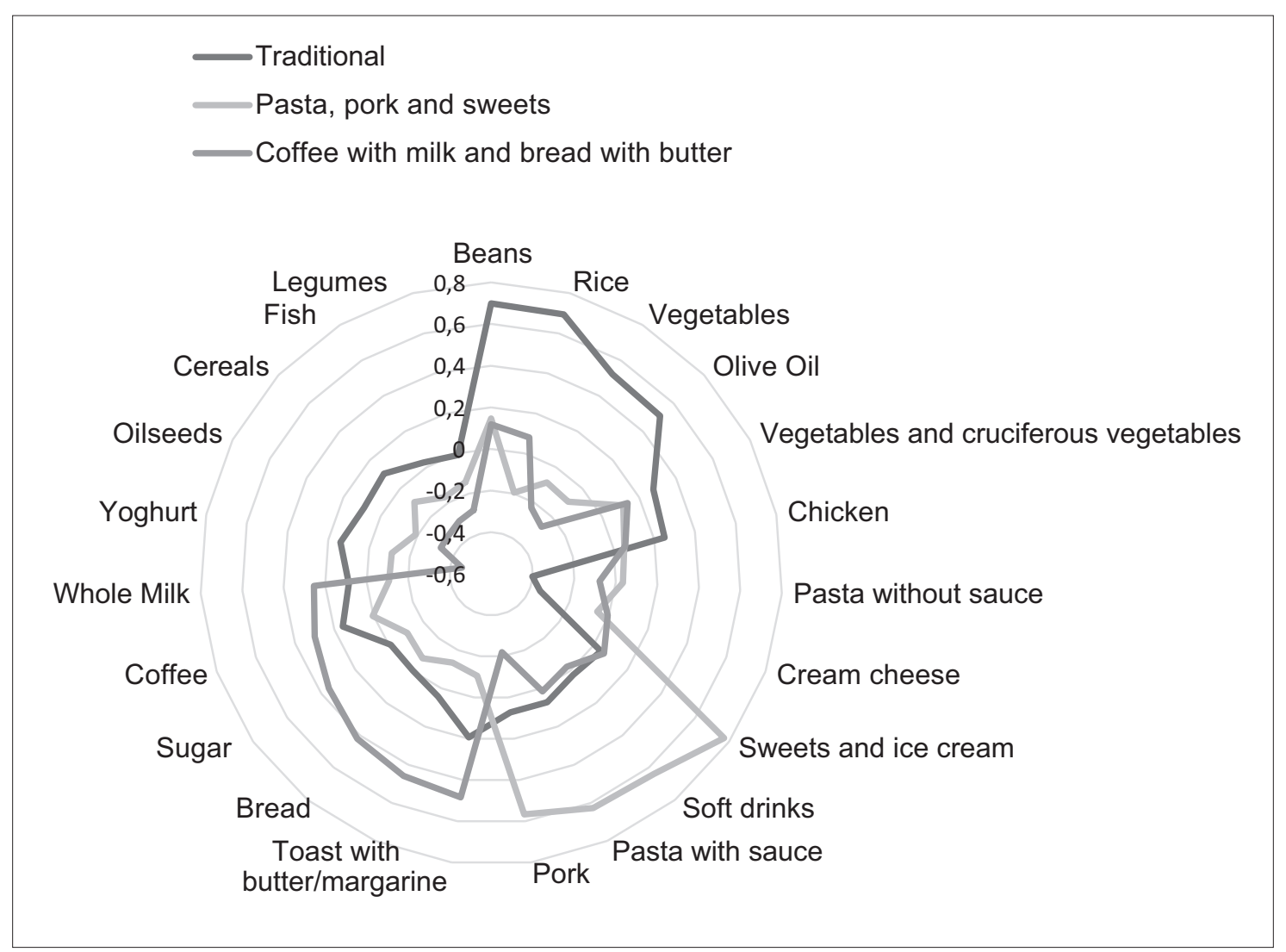

Figure 1. Graphical representation of food items that comprise dietary patterns of the elderly. São Caetano do Sul, São Paulo, 2015.

Table 2. Association between dietary patterns and the characteristics of the elderly. São Caetano do Sul, São Paulo, 2015.

\begin{tabular}{|c|c|c|c|c|c|c|c|}
\hline \multirow[t]{3}{*}{ Variables } & \multirow[t]{3}{*}{$\mathrm{N}(\%)$} & \multicolumn{2}{|c|}{ Traditional Pattern } & \multicolumn{2}{|c|}{$\begin{array}{l}\text { Pasta, pork and } \\
\text { sweets pattern }\end{array}$} & \multicolumn{2}{|c|}{$\begin{array}{l}\text { Coffee with milk } \\
\text { and bread with } \\
\text { butter pattern }\end{array}$} \\
\hline & & \multicolumn{2}{|c|}{ Linear regression } & \multicolumn{2}{|c|}{ Linear regression } & \multicolumn{2}{|c|}{ Linear regression } \\
\hline & & $\beta$ & $\mathrm{p}$ & $\beta$ & $\mathrm{p}$ & $\beta$ & $\mathrm{p}$ \\
\hline \multicolumn{8}{|l|}{ Gender } \\
\hline Female & $251(85.1)$ & & & & & & \\
\hline Male & $44(14.9)$ & 0.59 & $<0.001$ & 0.38 & 0.025 & - & \\
\hline \multicolumn{8}{|l|}{ Age range (years) } \\
\hline 60 to 69 & $137(46.4)$ & & & & & & \\
\hline 70 to 79 & $124(42.0)$ & - & & - & & -0.02 & 0.905 \\
\hline 80 or more & $34(11.5)$ & & & & & 0.55 & 0.004 \\
\hline \multicolumn{8}{|l|}{ Marital status } \\
\hline Married & $132(44.7)$ & & & & & & \\
\hline Separated/Divorced/Widowed & $163(55.3)$ & - & & -0.24 & 0.041 & - & \\
\hline \multicolumn{8}{|l|}{ Lives alone } \\
\hline Yes & $75(25.4)$ & & & & & & \\
\hline No & $220(74.6)$ & - & & - & & & \\
\hline
\end{tabular}


continued from Table 2

\begin{tabular}{lllll}
\hline Variables & $\mathrm{N}(\%)$ & Traditional Pattern & $\begin{array}{l}\text { Pasta, pork and } \\
\text { sweets pattern }\end{array}$ & $\begin{array}{l}\text { Coffee with milk } \\
\text { and bread with } \\
\text { butter pattern }\end{array}$ \\
& & Linear regression & Linear regression & $\begin{array}{l}\text { Linear regression } \\
\end{array}$ \\
& $\beta$ & $\mathrm{p}$ & $\beta$ & $\mathrm{p}$
\end{tabular}

$\begin{array}{ll}0-4 & 123(41.7) \\ 5-8 & 62(21.0) \\ 9-12 & 53(18.0) \\ 12 \text { or more } & 57(19.3)\end{array}$

Occupational activity

Work

$21(7.1)$

Retired

$184(62.4)$

$0.55 \quad 0.017 \quad-$

Homemaker

$86(29.2)$

$0.06 \quad 0.642$

Information not given

$4(1.3)$

$0.28 \quad 0.575$

Per capita income (MS: minimum salary)

No information

$6(2.0)$

No income

$29(9.8)$

Up to $1 \mathrm{MS}$

$62(21.0)$

$>1$ to $\leq 3 \mathrm{MS}$

$130(44.1)$

$>3 \mathrm{MS}$

$68(23.1)$

Smoker

$\mathrm{No}$

$282(95.6)$

Yes

$13(4.4)$

Nutritional status

Normal weight

$125(42.4)$

Underweight

$41(13.9)$

Overweight

$38(12.9)$

Obesity

$91(30.8)$

Waist circumference

Low risk

$52(17.6)$

High risk

53 (18.0)

Very high risk

$190(64.4)$

Physical Activity

Doesn't perform

45 (15.3)

Performs

$250(84.7) \quad 0.39 \quad 0.020$

Difficulty chewing

No

$263(89.2)$

Yes

$32(10.8)$

$-$

0.38

Dentition

Own teeth

$124(42.0)$

Dentures

$171(58.0) \quad-0.25$ 0.034

$-$ 


\section{DISCUSSION}

To characterize the food consumption of the elderly, three dietary patterns were identified, which helped with the understanding of the food choices of the elderly and their associated factors. This methodology was chosen as its results can be used for the planning and implementation of public policies. Although widely used in academia, research on the dietary patterns of the elderly on a national level is still scarce.

The Traditional pattern consisted of foods commonly consumed by the Brazilian population in their main meals: rice, beans, chicken, greens, vegetables, and olive oil, and was positively associated with male elderly persons and physical activity. In the study of Brazilian adults by Neumann et al. ${ }^{16}$, dietary patterns were associated with a risk of the development of cardiovascular disease, and the Traditional pattern, composed of cereals, beans and infusions, unlike the present study, was associated with the female gender. Ferreira et al. ${ }^{2}$ identified dietary patterns in the elderly, including a Traditional pattern, with composition similar to the present study, whose main components were rice and beans. Selem ${ }^{17}$ identified three dietary patterns in adults and elderly persons in the city of São Paulo, noting that one, also entitled Traditional (Rice, beans, butter/margarine, whole milk, coffee/tea and sugar), was positively associated with non-hypertensive individuals.

Nascimento et al. ${ }^{18}$ with the objective of identifying dietary patterns in different Brazilian regions, used data from a nationally representative sample and observed that elderly persons in the southeast region of the country are more related to a Mixed pattern (vegetables, fruits, root vegetables, breads, cookies, dairy products, fish, butter or margarine and sugary drinks) than the other pattern found, which was named Rice and Beans. Both the Traditional pattern found in the present study and the Mixed pattern of the Brazilian population indicated the habit of the elderly of consuming vegetables (greens and vegetables). The Traditional pattern items observed in the present study are similar to foods that belong to a pattern often called Prudent and associated with a reduced risk of chronic diseases and frailty in the elderly ${ }^{16,17,19}$, and these data may corroborate the association of the pattern with the practice of physical activity, and also reveal that part of the sample is composed of elderly people who traditionally consume foods considered to be "healthier" than other studies.

The second dietary pattern found was called Pasta, pork and sweets and was composed of pasta with sauce, pork, sweets and soft drinks. Compared with other scientific findings, it was noticed that, for the most part, the pasta and sweets appeared as isolated patterns, and not as positive factor loadings for the composition of a single pattern, as meals are composed of a variety of food items, and not only of one food, which ends up hampering the power of comparative analysis ${ }^{4,6,19-21}$. In the study by Selem ${ }^{17}$ the Contemporary pattern (soft drinks, savory snacks/ sandwiches/pizzas, yellow cheeses, pasta, sauces, alcoholic beverages, sweets and processed meats) was similar to the Pasta, pork and sweets pattern. It is also worth noting that these food items are commonly found in non-Brazilian studies and are named the Western standard, composed of foods that are easy to prepare $^{22}$, which may justify the positive association of this pattern with the male gender and retired individuals, as was also observed by Selem ${ }^{17}$. This is a relevant finding for primary health care teams, which can be used to stimulate retired elderly people to continue giving preference to more "traditional" meals, and to warn that in the majority, foods that are easy to prepare and eat possess excess sodium, sugars and fats, damaging the health of those who consume them more often.

The third dietary pattern entitled Coffee with milk and bread and butter (butter/margarine, toast, bread, sugar, coffee and whole milk) was associated with elderly people aged 80 years or older and with difficulty chewing. Food items that make up this pattern usually make up the breakfast and snacks of Brazilians, especially in the southeast, or substitute main meals. Santos et al. ${ }^{3}$ identified dietary patterns in adult and elderly meals in the city of São Paulo, and found the Coffee with milk and bread pattern present at dinner. A qualitative study that sought to identify obstacles to the consumption of fruit and vegetable in adults and elderly people in Belo Horizonte, demonstrated the discontinuity of the habit of eating dinner, highlighted by the following discourse: "I drink milk, eat a piece of bread, but I rarely eat a proper dinner..."23. This is because these foods 
are easier to acquire, prepare and consume, due to issues related to the reduction of economic power and the chewing difficulties presented by the elderly, especially long-lived elderly persons, and should become a target of actions of nutritional attention and oral health for this age range, as the substitution of a main meal for a snack in individuals with greater nutritional needs than others, can increase frailty in the development of diseases, as well as making effective treatment more difficult.

In addition, studies have indicated a preference for the Coffee with milk and bread pattern among Brazilian elderly men, as described by Freitas et al. ${ }^{24}$ in an analysis of the foods most consumed by the elderly, in which whole milk occupied fifth position and French bread seventh. Data from the most recent Pesquisa de Orçamentos Familiares (Family Budget Survey) (POF) 2008-2009 showed that when the consumption of drinks among adolescents, adults and the elderly is compared, whole milk was consumed in the greatest quantities in the age groups older than 60 years ${ }^{25}$. A study by Nascimento et al. ${ }^{18}$, which used the same data, showed that among foods belonging to the main food pattern of the elderly in the southeast of Brazil were bread, dairy products and butter/ margarine.

Massarani et al. ${ }^{26}$ conducted a study using data from the National Food Survey, evidencing that dietary patterns are directly related to family aggregation in the Brazilian population, describing the patterns: Traditional snack (coffee, bread, fats and oils, and cheese), Large traditional meal (rice, beans and other vegetables, and meats), and Fast food style snacks (sandwiches, processed meats, soft drinks, salads and pizzas), which were similar to the patterns identified in the present study, and which suggest the influence of family in lifelong eating habits.

It should be noted that although the fruit group did not appear in any dietary pattern in the present study, the frequency of fruit consumption was observed in all the other samples, with more than half of the elderly $(58 \%)$ consuming three or more fruits daily ${ }^{27}$, and Figueira et al. ${ }^{28}$ stating that one of the factors that promotes fruit consumption is that such items are eaten in intervals between meals, and perhaps because of this are not associated with a particular eating occasion, together with other food items.
One important point to consider is the use of factorial analysis by the principal components method. This analysis and the identification of patterns are described in literature as subjective, as it is up to the researcher to decide and justify, with the aid of other statistical analyzes, the food grouping, the number of factors to be extracted, and the nomenclature adopted for the patterns, which may hamper the power of comparison with other studies, in addition to the analysis of differences in social, economic and demographic characteristics ${ }^{29}$. However, it should be considered that the similarity of the methodology chosen for data analysis, when searching for dietary patterns, allows us to establish a profile of food behavior that allows the explanation of certain health outcomes associated with the pattern. Furthermore, Newby et al. ${ }^{30}$ observed that even with less comparative power, studies that demonstrated similarity in the constituents of the patterns identified can be considered to possess reasonable reproducibility and data consistency, corroborating the findings of the present study, and can serve as a support for public policies and interventions for the public studied.

It is worth highlighting some limitations of the present study, such as the use of a non-probabilistic sample, which reduces the power of comparison between Brazilian and non-Brazilian population studies. However, to reduce this bias, the elderly were selected from different neighborhoods in the city, with different social, demographic and economic characteristics, but which were also similar to the official data of the Census of the municipal region ${ }^{31}$. Another possible limitation is age, as common alterations in aging, such as concentration difficulty and decreased memory, may increase the duration of the interview and require more attention on the part of the interviewer. In this sense, the training of the research nutritionists and the available space for data collection were essential to ensure the reliability of the information collected and used in the analysis and the results obtained.

\section{CONCLUSION}

Three dietary patterns were identified in the elderly: the Traditional pattern, which was associated with males and lifestyle (physical activity), the Pastas, 
pork and sweets pattern, which was associated with gender and being retired, and the Coffee with milk and bread and butter, which was associated with elderly persons aged 80 years or older and who had difficulty chewing. The results of the present study serve as a basis for the development of intervention strategies and specific public policies in this municipal region and age group, as municipal-level studies are important, as they can identify differences that cannot always be observed in national studies. Identifying the food patterns of the elderly population contributes to the discussion among care professionals about the impact of food and nutrition on the quality of life and health of the elderly population in Brazil.

\section{REFERENCES}

1. Academy of Nutrition and Dietetics. Position of the academy of nutrition and dietetics: total diet approach to healthy eating. J Acad Nutr Diet. 2013;113(2):307-17.

2. Ferreira PM, Papini SJ, Corrente JE. Diversity of eating patterns in older adults: a new scenario? Rev Nutr. 2014;27(1):67-79.

3. Santos RO, Fisberg RM, Marchioni DML, Baltar VT. Dietary patterns for meals of Brazilian adults. Brit J Nutr. 2015;114(5):822-8.

4. Hamer M, McNaughton AS, Bates CJ, Mishra GD. Dietary patterns, assessed from a weighed food record, and survival among elderly participants from the United Kingdom. Eur J Clin Nutr. 2010;64(8):853-61.

5. Langsetmo L, Hanley DA, Prior JC, Barr SI, Anastassiades T, Towheed T, et al. Dietary patterns and incident low-trauma fractures in postmenopausal women and men aged $\geq 50 \mathrm{y}$ : a population-based cohort study. Am J Clin Nutr. 2011;93(1):192-9.

6. Mattei J, Noel SE, Tucker KL. A meat, processed meat, and french fries dietary pattern is associated with high allostatic load in Puerto Rican older adults. J Am Diet Assoc. 2011;111(10):1498-1506.

7. Torres SJ, Lautenschlager NT, Wattanapenpaiboon N, Greenop KR, Beer C, Flicker L, et al. Dietary patterns are associated with cognition among older people with mild cognitive impairment. Nutrients. 2012;4(11):1542-51.

8. Anderson AL, Harris TB, Tylavsky FA, Perry SE, Houston DK, Lee JS, et al. Dietary patterns, insulin sensitivity and inflammation in older adults. Eur J Clin Nutr. 2012;66:18-24.

9. Hair JF, Anderson RE, Tatham RL. Análise multivariada de dados. $5^{\mathrm{a}}$ ed. Porto Alegre: Bookman; 2005.

10. Saúde, Bem-estar e Envelhecimento, Organização Pan Americana de Saúde. Questionário de coleta de dados completo [Internet]. São Paulo: Universidade de São Paulo, Faculdade de Saúde Pública; 2000 [acesso em 08 de dezembro de 2014]. Disponível em: http:// www.fsp.usp.br/sabe/Artigos/Questionario_2000.pdf
11. Organização Pan Americana de Saúde. Encuesta Multicêntrica - Salud Bienestar y Envejecimiento (SABE) en America Latina e el Caribe. In: $36^{\mathrm{a}}$ Reunión Del Comitê Asesor de Investigaciones em Salud : informe preliminar [Internet]; 9-11 jul. 2001; Kingston 2001. Whashington, DC: OPAS; 2001 [acesso em 13 de fevereiro de 2014]. Disponível em: http://www.opas.org/program/sabe.htm

12. University of Minnesota Nutrition. Data System Reaserch - NDSR [Internet]. Minneapolis: University of Minnesota; 2013.

13. Universidade de São Paulo, Faculdade de Saúde Pública, Grupo de Pesquisa de Avaliação do Consumo Alimentar. Manual de avaliação do consumo alimentar em estudos populacionais: a experiência do inquérito de saúde em São Paulo (ISA). Fisberg RM, Marchioni DML, organizadoras. São Paulo: Faculdade de Saúde Pública; 2012.

14. Hair JF, Anderson RE, Tatham RL, Black WC. Multivariate data analysis with readings. $4^{\mathrm{a}} \mathrm{ed}$. New Jersey: Prentice Hall; 1995.

15. Pestana MH, Gageiro JN. Análise de dados para ciências sociais: a complementaridade do SPSS. Lisboa: Edições Sílabo; 2005.

16. Neumann AICP, Martins IS, Marcopito LF, Araujo EAC. Padrões alimentares associados a fatores de risco para doenças cardiovasculares entre residentes de um município brasileiro. Rev Panam Salud Publica. 2007;22(5):329-39.

17. Selem SSC. Padrões da dieta e hipertensão em adultos e idosos de São Paulo [dissertação]. São Paulo: Universidade de São Paulo, Faculdade de Saúde Pública; 2012.

18. Nascimento S, Barbosa FS, Sichieri S, Pereira RA. Dietary availability patterns of the brazilian macroregions. Nutr J. 2011;10:79.

19. Léon-Muñoz LM, García-Esquinas E, LópezGarcía E, Banegas JR, Rodríguez-Artalejo F. Major dietary patterns and risk of frailty in older adults: a prospective cohort study. BMC Med. 2015;13:11. 
20. Pala V, Sieri S, Masala G, Palli D, Panico S, Vineis $\mathrm{P}$, et al. Associations between dietary pattern and lifestyle, anthropometry and other health indicators in the elderly participants of the EPIC-Italy cohort. Nutr Metab Cardiovasc Dis. 2006;16(3):186-201.

21. López EP, Rice C, Weddle DO, Rahill GJ. The relationship among cardiovascular risk factors, diet patterns, alcohol consumption, and ethnicity among women aged 50 years and older. J Am Diet Assoc. 2007;108(2):248-56.

22. Samieri C, Jutand MA, Féart C, Capuron L, Letenneur L, Barberger-Gateau P. Dietary patterns derived by hybrid clustering method in older people: association with cognition, mood, and self-rated health. J Am Diet Assoc. 2008;108(9):1461-71.

23. Bailey RL, Mitchel DC, Miller CK, Still CD, Jensen GL, Tucker KL, et al. A dietary screening questionnaire identifies dietary patterns in older adults. J Nutr. 2007;137(2):421-6.

24. Figueira TR, Lopes ACS, Modena CM. Barreiras e fatores promotores do consumo de frutas e hortaliças entre usuários do Programa Academia da Saúde. Rev Nutr. 2016;29(1):85-95.

25. Freitas AMP, Philippi ST, Ribeiro SML. Lista de alimentos relacionados ao consumo alimentar de um grupo de idosos: análises e perspectivas. Rev Bras Epidemiol. 2011;14(1):161-77.
26. Instituto Brasileiro de Geografia Estatística. Pesquisa de orçamentos familiares 2008-2009: análise do consumo alimentar pessoal no Brasil [Internet]. Rio de Janeiro: IBGE; 2011 [acesso em 28 jan. 2016]. Disponível em: http://www.ibge.gov.br/home/estatistica/populacao/ condicaodevida/pof/2008_2009_analise_consumo/ pofanalise_2008_2009.pdf

27. Massarani FA, Cunha DB, Muraro AP, Souza BSN, Sichieri R, Yokoo EM. Agregação familiar e padrões alimentares na população brasileira. Cad Saúde Pública. 2015;31(12):2535-45.

28. Secafim MV, Previdelli NA, Marques KM, Ferreira MPN, Freitas TI, Goulart RMM, et al. Avaliação do consumo de frutas por idosos de São Caetano do Sul, São Paulo, Brasil. Geriatr Gerontol Aging. 2016;10(2):57-63.

29. Fisberg RM, Slater B, Marchioni DML, Martin LA. Inquéritos alimentares: métodos e bases científicos. São Paulo: Manole; 2005.

30. Newby PK, Muller D, Hallfrisch J, Andres R, Tucker KL. Food patterns measured by factor analisys and anthropometric changes in adults. Am J Clin Nutr. 2003;80(2):504-13.

31. Instituto Brasileiro de Geografia Estatística. Censo Demográfico 2010: São Caetano do Sul. Características da população - Amostra [Internet]. Rio de Janeiro: IBGE; [1995] -. [acesso em 07 mar. 2016]. Disponível em: http://www.ibge.gov.br/ cidadesat/topwindow.htm?1 